\title{
THE MULTIPLE CHOICE PROBLEM WITH INTERACTIONS BETWEEN CRITERIA
}

\author{
Luiz Flavio Autran Monteiro Gomes ${ }^{1 *}$, \\ Maria Augusta Soares Machado ${ }^{1}$ and Luis Alberto Duncan Rangel ${ }^{2}$
}

Received May 14, 2014 / Accepted August 12, 2015

\begin{abstract}
An important problem in Multi-Criteria Decision Analysis arises when one must select at least two alternatives at the same time. This can be denoted as a multiple choice problem. In other words, instead of evaluating each of the alternatives separately, they must be combined into groups of $n$ alternatives, where $n=2$. When the multiple choice problem must be solved under multiple criteria, the result is a multi-criteria, multiple choice problem. In this paper, it is shown through examples how this problem can be tackled on a bipolar scale. The Choquet integral is used in this paper to take care of interactions between criteria. A numerical application example is conducted using data from SEBRAE-RJ, a nonprofit private organization that has the mission of promoting competitiveness, sustainable development and entrepreneurship in the state of Rio de Janeiro, Brazil. The paper closes with suggestions for future research.
\end{abstract}

Keywords: Multi-Criteria Decision Analysis, bipolar Choquet integral, multiple choice problem, formation of portfolios, fuzzy logic.

\section{INTRODUCTION}

The project portfolio management process involves different stages of decision making. At the end of those stages, projects that add value to organizations are selected and prioritized. Companies that work with multiple projects require a vision or integrated form of management that encompasses all of the projects from their portfolios. The methods that are used to form a portfolio of projects tend to emphasize the importance of uncertainty as a process variable. The term uncertainty usually refers to both the resources and the results that must be achieved (He \& Zhou, 2011; Yu et al., 2012). This statement is especially true in a multiple interacting criteria context.

\footnotetext{
*Corresponding author.

${ }^{1}$ Ibmec/RJ, Av. Presidente Wilson, 118, sala 1110, 20030-020 Rio de Janeiro, RJ, Brasil. Tel: +55 21 4503-4053

- E-mails: autran@ibmecrj.br; mmachado@ibmecrj.br

${ }^{2}$ EEIMVR/UFF, Av. dos Trabalhadores, 420, 27255-125 Volta Redonda, RJ, Brasil. Tel: +55 24 9948-7882

- E-mail: duncan@metal.eeimvr.uff.br
} 
The issue of dependency between criteria has been approached by different authors in MultiCriteria Decision Analysis (Čančer, 2010; Dalalah et al., 2012; Öztürk, 2006; Roy, 2009). However, that issue has been virtually untouched within the context of portfolio selection under multiple criteria.

Selecting a portfolio of projects is a problem that has been approached using Multi-Criteria Decision Analysis (Vetschera \& Almeida, 2012; Anagnostopoulos \& Mamanis, 2010; Carazo et al., 2010). However, in many cases when portfolios must be selected under multiple criteria, the interactions among the criteria are not considered as much as they should be, and additive aggregation procedures are used. A mathematical model that has been quite useful for modeling the interactions between criteria is the Choquet integral (Choquet, 1953). The objective of this paper is to show how the bipolar Choquet integral can be used for determining two or three combinations of choices for projects to be performed at the same time under multiple criteria, given that there are interactions between criteria. Ordering the two or three project combinations is indeed a multiple choice problem. A numerical application example is conducted using the data from Gomes et al. (2009).

\section{THE CHOQUET INTEGRAL AS A MULTICRITERIA RANKING MODEL IN THE UNIPOLAR SCALE}

The Choquet integral makes use of fuzzy measures. Those measures are very important for problems that require reliability (in a sense that an element belongs to a set) and plausibility which is dual to reliability. The fuzzy measures also assign different degrees of importance to preferences and verify whether the criteria are met.

Following Grabisch \& Labreuche (2010), consider the set $X=X_{1} \times X_{2} \ldots \times X_{n}$ of feasible alternatives. The decision maker has preferences with respect to $X$ that are expressed by a binary relation of the type $\succsim$.

Now consider the function that is given by $x \geq y \rightarrow F\left(\mu_{1}\left(x_{1}\right), \ldots, \mu_{n}\left(x_{n}\right)\right) \geq F\left(\mu_{1}\left(y_{1}\right), \ldots\right.$, $\left.\mu_{n}\left(y_{n}\right)\right)$, where $F$ is the Choquet integral and $\mu_{i}: X_{i} \rightarrow S, i=1, \ldots, n$ are aggregation functions. $S \subset R^{+}$is a scale that represents the decision maker's preferences.

There are two types of scales: the first scale, the limited unipolar scale, applies when $S=$ $[0 ; 1]$, where zero means the absence of a property and 1 means the total certainty about the existence of such a property. In modeling, one can affirm the existence in $X_{i}$ of two elements that have the notations $U_{i}$ and $P_{i}$, where $U_{i}$ is an element of $X_{i}$ that represents the complete dissatisfaction of the decision maker and $P_{i}$ represents his complete satisfaction, then $\mu_{i}\left(U_{i}\right)=0$ and $\mu_{i}\left(P_{i}\right)=1$. The second scale, the unlimited unipolar scale, applies when $S=R^{+}$. This scale serves to represent the priorities and relative importance. For convenience, we use the notation $\mu_{i}\left(S_{i}\right)=1$.

According to Sugeno (1974), the function $u: 2^{N} \rightarrow R$ is a capacity if $u(\phi)=0$. A capacity $\mu$ that satisfies $\mu(A) \leq \mu(B), A \subseteq B$ is a fuzzy measure. This fuzzy capacity is normalized if $\mu(N)=1$, where $N$ is the set of natural numbers. The fuzzy capacity is additive if, for all 
disjoint sets $A, B \subseteq N$, one has $\mu(A \cup B)=\mu(A)+\mu(B)$. It is symmetrical if, for all subsets $A, B$, we have $|A|=|B| \Rightarrow \mu(A)=\mu(B)$.

The formal definition of the discrete Choquet integral in a unipolar scale can be defined as follows: Let $f: N \rightarrow R^{+}$to be the Choquet integral $f$ in relation to a capacity $\mu$ given by:

$$
C_{\mu}(f)=\sum\left(f_{\sigma(i)}-f_{\sigma(i-1)}\right) \mu\left(\left\{\sigma_{1}, \ldots, \sigma_{n}\right\}\right)
$$

where $\sigma$ is a permutation in $N$ such that $f_{\sigma_{1}} \leq \ldots \leq f_{\sigma_{n}}$ and $f_{\sigma_{0}}=0$.

To construct an example, assume that the scores of 4 students in 3 subjects are as shown in Table 1.

Table 1 - Students' evaluations in 3 subjects.

\begin{tabular}{|l|c|c|c|c|}
\hline \multirow{2}{*}{ Criterion } & \multicolumn{4}{|c|}{ Alternative } \\
\cline { 2 - 5 } & Student A & Student B & Student C & Student D \\
\hline Subject 1 & 4 & 3 & 1 & 2 \\
\hline Subject 2 & 6 & 5 & 6 & 5 \\
\hline Subject 3 & 3 & 5 & 3 & 2 \\
\hline
\end{tabular}

The dean of the school wants to give a full scholarship to a student by sticking to the following rule: every chosen student must be good in subjects 1, 2 and 3 (exactly in this order, that is subject 1 is more important than subject 2 and subject 2 is more important than subject 3) (i.e. Subject $1 \succ$ Subject $2 \succ$ Subject 3 ).

The ordering of these 4 students can be determined by using the Choquet integral as shown in Table 2. The steps below are then followed.

\section{Step 1 - Determining the fuzzy measures}

A fuzzy measure indicates the degree of evidence that an element belongs to a set. It was used a 2-additive model and Shapley-Schubik index to determine the fuzzy measures.

For example, considering three subjects in this order Subject $1 \succ$ Subject $2 \succ$ Subject 3. The fuzzy measures used in this example were:

$$
\begin{array}{llll}
\mu(\{1,2,3\})=1, & \mu(\phi)=0, & \mu(\{1\})=0.35, & \mu(\{2\})=0, \\
\mu(\{3\})=0, & \mu(\{1,2\})=0.34, & \mu(\{1,3\})=0, & \mu(\{2,3\})=0.33 .
\end{array}
$$

\section{Step 2: Calculating the Choquet integral}

These calculations are performed by summing the values along each column. This sum gives the values of the Choquet integral. The ranking of the alternatives that are provided by the Choquet integral is then obtained by ordering these alternatives from the highest to the lowest values. The results are presented in Table 2.

The resulting order is: Student $A \succ$ Student $C \succ$ Student $D \succ$ Student B. This arrangement means that Student A is preferable to the other students. 
Table 2 - Ranking obtained by using the Choquet integral in the unipolar scale.

\begin{tabular}{|c|c|c|c|c|}
\hline \multirow{2}{*}{ Criterion } & \multicolumn{4}{|c|}{ Alternatives } \\
\hline & Student A & Student B & Student C & Student D \\
\hline Subject 1 & $\begin{array}{l}4 \mu(\{1\}) \\
=4 \cdot 0.35 \\
=1.4\end{array}$ & $\begin{array}{l}3 \mu(\{1\}) \\
=3 \cdot 0.35 \\
=1.05\end{array}$ & $\begin{array}{l}\mu(\{1\}) \\
=0.35\end{array}$ & $\begin{array}{l}2 \mu(\{1\}) \\
=(2) \cdot 0.35 \\
=0.7\end{array}$ \\
\hline Subject 2 & $\begin{array}{l}2 \mu(\{1,2\}) \\
=(6-4) \cdot 0.34 \\
=0.68\end{array}$ & $\begin{array}{l}2 \mu(\{1,2\}) \\
=(5-3) \cdot 0.34 \\
=0.68\end{array}$ & $\begin{array}{l}5 \mu(\{1,2\}) \\
=(6-1) \cdot 0.34 \\
=1.7\end{array}$ & $\begin{array}{l}3 \mu(\{1,2\}) \\
=(5-2) \cdot 0.34 \\
=1.02\end{array}$ \\
\hline Subject 3 & $\begin{array}{l}3 \mu(\{2,3\}) \\
=3 \cdot 0.33 \\
=0.99\end{array}$ & $\begin{array}{l}(5-5) \mu(\{2,3\}) \\
=0\end{array}$ & $\begin{array}{l}(6-3) \mu(\{2,3\}) \\
=(3) \cdot 0.33 \\
=0.99\end{array}$ & $\begin{array}{l}7 \mu(\{2,3\}) \\
=(5-2) \cdot 0.33 \\
=0.99\end{array}$ \\
\hline Choquet integral & $\begin{array}{l}1.4+0.68+0.99 \\
=3.07\end{array}$ & $\begin{array}{l}1.05+0.68+0 \\
=1.73\end{array}$ & $\begin{array}{l}0.35+1.7+0.99 \\
=3.04\end{array}$ & $\begin{array}{l}0.7+1.02+0.99 \\
=2.71\end{array}$ \\
\hline Ordering & 1 & 4 & 2 & 3 \\
\hline
\end{tabular}

\section{THE CHOQUET INTEGRAL IN THE BIPOLAR SCALE}

Using the same notation as in the previous section, for the bipolar Choquet we have the following (Grabisch \& Labreuche, 2005):

Let $f: N \rightarrow R^{n}, A \subseteq R^{n}$ be the Choquet integral of $f$ with respect to the capacity $\mu$ given by

$$
C_{\mu}(f)=\sum_{i=1}^{n}[f(\sigma(i))-f(\sigma(i-1))] \mu\left(A_{\sigma_{i}}\right),
$$

where $\sigma$ is a permutation in $N$ such that $f_{\sigma(1)} \leq \ldots \leq f_{\sigma(n)}$ and $f_{\sigma(0)}=0$.

According to Greco \& Figueira (2003), given a finite set $J=\{1,2, \ldots, n\}$, a fuzzy measure $\mu$ is a function of the form: $\mu: 2^{J} \rightarrow[0,1]$ such that $\mu(\phi)=0, \mu(J)=1$ (boundary conditions) and $\mu(C)=\mu(D)$ if $D \subseteq C, \forall C, D \subseteq J$ (monotonicity condition).

Let $P(J)$ be a set of pairs of subsets of

$$
J: P(J)=\{(C, D), C, D \subseteq J, C \bigcap D=\phi\} .
$$

A bi-capacity $\mu$ in $J$ is a function $\mu: P(J) \rightarrow[0,1] X[0,1]$ such that $\mu(C, \phi)=(c, 0)$ and $\mu(\phi, D)=(0, d), c, d \in[0,1] ; \mu(J, \phi)=(1,0)$ and $\mu(\phi, J)=(0,1)$ (boundary conditions). For each $(C, D),(E, F) \in P(J)$ such that $E \subseteq C, D \subseteq F$, we have $\mu(C, D)=(c, d)$ and $\mu(E, F)=(e, f), e, f \in[0,1]$ with $c \geq e$ and $d \geq f$ (monotonicity condition). We use the following notation: $\mu^{+}(C, D)=c, \mu^{-}(C, D)=d$. A bi-capacity $\hat{\mu}$ on the set $J$ is a function $\hat{\mu}: P(J) \rightarrow[-1,1]$ such that $\hat{\mu}(\phi, \phi)=0 ; \hat{\mu}(J, \phi)=1$ and $\hat{\mu}(\phi, J)=-1$ (boundary conditions). If $E \subseteq C, D \subseteq F$, then $\hat{\mu}(C, D) \geq \hat{\mu}(E, F)$ (monotonicity condition). From each bi-polar capacity $\mu$ in $J$, we can obtain a bi-capacity $\hat{\mu}$ in $J: \hat{\mu}(C, D)=\mu^{+}(C, D)-$ $\mu^{-}(C, D), \forall C, D \in P(J)$ (Greco \& Figueira, 2003).

For each $x \in R^{n}: x^{+}=\max \{x, 0\}$ is the positive part of $x$; for each $x \in R: x-=\max \{-x, 0\}$ is the negative part of $x$; for each $x \in R: x^{+}=\left(x_{1}^{+}, x_{2}^{+}, \ldots, x_{n}^{+}\right)$is the positive part of 
$x\left(x_{1}, x_{2}, \ldots, x_{n}\right) \in R^{n}$; and $x^{-}=\left(x_{1}^{-}, x_{2}^{-}, \ldots, x_{n}^{-}\right)$is the negative part of $x\left(x_{1}, x_{2}, \ldots, x_{n}\right) \in$ $R^{n}$. Given $x \in R^{n}$, we consider a permutation ( $\cdot$ ) of the elements of $J$ such that $\left|x_{(1)}\right| \leq\left|x_{(2)}\right| \leq$ $\cdots \leq\left|x_{(j)}\right| \leq\left|x_{(n)}\right|$. For each element $j \in J$, we have two subsets, $C(j)=\left\{i \in J: x_{i} \geq\left|x_{(j)}\right|\right\}$ and $D(j)=\left\{i \in J:-x_{i} \geq\left|x_{(j)}\right|\right\}$. Considering a bi-capacity $\mu$ in $J$ and a vector $x \in R^{n}$, we can define the positive part of the bipolar Choquet integral as follows:

$$
C h^{+}(x, \mu)=\sum_{j \in J^{>}}\left(\left|x_{(j)}\right|-\left|x_{(j-1)}\right| \mu^{+}\left(C_{(j)}, D_{(j)}\right)\right),
$$

where $J \geq\left\{j \in J /\left|x_{j}\right|>0\right\}$. In the same way, we can write the negative part of the bipolar Choquet integral as follows: $\mathrm{Ch}^{-}(x, \mu)=\sum_{j \in J^{>}}\left(\left|x_{(j)}\right|-\left|x_{(j-1)}\right| \mu^{-}\left(C_{(j)}, D_{(j)}\right)\right)$. Therefore, the bipolar Choquet integral is $C h^{B}(x, \mu)=C^{+}(x, \mu)+C h^{-}(x, \mu)$.

To illustrate the use of the bipolar Choquet integral, we now consider an example of the evaluation of apartments for rent based on three alternatives: near downtown, near a subway station and low cost, which are given in Table 3. In this example, we have used a Likert scale, with which the opinions of experts varying from 1 (worst value) to 5 (best value). To select the best apartment, the client expresses his preferences as follows: $(i)$ for an apartment near downtown, a low price is more important than being near the subway; therefore, apartment \#1 is better than apartment \#2; and (ii) for an apartment far from downtown, being near the subway station is more important than a low price; therefore, apartment \#3 is better than apartment \#4.

Table 3 - Decision matrix for a bipolar example.

\begin{tabular}{|c|c|c|c|c|}
\hline \multirow{2}{*}{ Criterion } & \multicolumn{4}{|c|}{ Alternative } \\
\cline { 2 - 5 } & $\begin{array}{c}\text { Apartment } \\
\# 1\end{array}$ & $\begin{array}{c}\text { Apartment } \\
\# 2\end{array}$ & $\begin{array}{c}\text { Apartment } \\
\# 3\end{array}$ & $\begin{array}{c}\text { Apartment } \\
\# 4\end{array}$ \\
\hline Near downtown & 5 & 5 & 2 & 2 \\
\hline Near subway station & 4 & 5 & 5 & 4 \\
\hline Near subway station & 3 & 4 & 4 & 3 \\
\hline
\end{tabular}

\section{Step 1 - Determining the fuzzy measures}

Consider the following ordering of criteria: (i) low price $\succ$ near subway station for an apartment near downtown; and (ii) near subway station $\succ$ low price for an apartment far from downtown. This arrangement allows us to establish a relation between the fuzzy measures using a 2additive model and the Shapley-Chubik index [Grabisch \& Labreuche (2010)]. Those measures are presented below:

$$
\begin{array}{llll}
\mu(\{1,2,3\})=1, & \mu(\phi)=0, & \mu(\{1\})=0.39, & \mu(\{2\})=0, \\
\mu(\{3\})=0, & \mu(\{1,2\})=0.33, & \mu(\{1,3\})=0, & \mu(\{2,3\})=0.31
\end{array}
$$

\section{Step 2 - Calculating the Choquet integral}

In Table 4, we present the rank ordering obtained by using the bipolar Choquet integral. 
Computations are performed by determining the Min and Max values along each column. The MaxMin operator gives the values of the Choquet integral. The ranking of the alternatives that are provided by the Choquet integral is then obtained by ordering these alternatives from the highest to the lowest values. The results are presented in Table 4.

Table 4 - Rank ordering for a bipolar example.

\begin{tabular}{|c|c|c|c|c|}
\hline \multirow{2}{*}{ Criterion } & \multicolumn{4}{|c|}{ Alternatives } \\
\hline & Apartment \#1 & Apartment \#2 & Apartment \#3 & Apartment \#4 \\
\hline Near downtown & $\begin{array}{l}5 \mu(\{1\}) \\
=5 \cdot 0.39 \\
=1.95\end{array}$ & $\begin{array}{l}5 \mu(\{1\}) \\
=5 \cdot 0.39 \\
=1.95\end{array}$ & $\begin{array}{l}3 \mu(\{1\}) \\
=3 \cdot 0.39 \\
=0.78\end{array}$ & $\begin{array}{l}3 \mu(\{1\}) \\
=3 \cdot 0.39 \\
=0.78\end{array}$ \\
\hline Near subway station & $\begin{array}{l}\mu(\{1,2\}) \\
=(5-4) \cdot 0.33 \\
=0.33\end{array}$ & $\begin{array}{l}\mu(\{1,2\}) \\
=(5-5) \cdot 0.33 \\
=0\end{array}$ & $\begin{array}{l}\mu(\{1,2\}) \\
=(5-2) \cdot 0.33 \\
=0.99\end{array}$ & $\begin{array}{l}\mu(\{1,2\}) \\
=(4-2) \cdot 0.33 \\
=0.66\end{array}$ \\
\hline Low price & $\begin{array}{l}(4-3) \mu(\{2,3\}) \\
=1 \cdot 0.31 \\
=0.31\end{array}$ & $\begin{array}{l}(5-4) \mu(\{2,3\}) \\
=1 \cdot 0.31 \\
=0.31\end{array}$ & $\begin{array}{l}(5-4) \mu(\{2,3\}) \\
=1 \cdot 0.31 \\
=0.31\end{array}$ & $\begin{array}{l}(4-3) \mu(\{2,3\}) \\
=1 \cdot 0.31 \\
=0.31\end{array}$ \\
\hline Min operator & $\begin{array}{l}1.95 \times 0.33 \times 0.31 \\
=0.2\end{array}$ & $\begin{array}{l}1.95 \times 0 \times 0.31 \\
=0\end{array}$ & $\begin{array}{l}0.78 \times 0.99 \times 0.31 \\
=0.24\end{array}$ & $\begin{array}{l}0.78 \times 0.66 \times 0.31 \\
=0.16\end{array}$ \\
\hline Max operator & $\begin{array}{l}1.95+0.33+0.31 \\
=2.59\end{array}$ & $\begin{array}{l}1.95+0+0.31 \\
=2.26\end{array}$ & $\begin{array}{l}0.78+0.99+0.31 \\
=2.08\end{array}$ & $\begin{array}{l}0.78+0.66+0.31 \\
=1.75\end{array}$ \\
\hline Choquet integral & 2.59 & 2.26 & 2.08 & 1.75 \\
\hline Rank Ordering & 1 & 2 & 3 & 4 \\
\hline
\end{tabular}

By using the bipolar Choquet integral the logic and desired solution is obtained. This solution is the following: Apartment \#1 $\succ$ Apartment \#2 and Apartment \#3 $\succ$ Apartment \#4.

\section{THE SEBRAE-RJ CASE STUDY}

A numerical application example is conducted using data from Gomes et al. (2009). SEBRAE$\mathrm{RJ}$ is a non-profit private organization that has the mission of promoting competitiveness and sustainable development and encouraging entrepreneurship in the state of Rio de Janeiro, Brazil. In conjunction with the Strategies and Guidelines area of that organization, nine criteria were defined to evaluate different development projects. These criteria were $C_{1}=$ cost of project; $C_{2}=$ generated revenue/total cost of project; $C_{3}=$ degree of synergy in the use of SEBRAERJ's products in the project; $C_{4}=$ capacity to contribute to the sustainable development of the region; $C_{5}=$ capacity to interact with other sectors of the economy; $C_{6}=$ capacity to generate employment and income; $C_{7}=$ degree of adherence of the partnerships in the management as well as governance of the project; $C_{8}=$ chance of success; and $C_{9}=$ degree of visibility that the project would bring to SEBRAE-RJ. The decision matrix is presented in Table 5. In Table 5, 'Cr' stands for 'Criterion'. 
Table 5 - Decision matrix for the SEBRAE-RJ Case Study.

\begin{tabular}{|c|c|c|c|c|c|c|c|c|c|c|c|}
\hline \multirow{2}{*}{$\mathrm{Cr}$} & \multicolumn{10}{|c|}{ Projects } \\
\cline { 2 - 14 } & $P_{1}$ & $P_{2}$ & $P_{3}$ & $P_{4}$ & $P_{5}$ & $P_{6}$ & $P_{7}$ & $P_{8}$ & $P_{9}$ & $P_{10}$ & $P_{11}$ \\
\hline$C_{1}$ & 775.79 & 393.06 & 343.93 & 1572.24 & 327.55 & 884.38 & 2354.2 & 884.39 & 929.54 & 982.67 & 3684.94 \\
\hline$C_{2}$ & 0.08 & 0.06 & 0.63 & 0.10 & 0.10 & 0.19 & 0.09 & 0.09 & 0.12 & 0.31 & 0.06 \\
\hline$C_{3}$ & 4 & 6 & 4 & 6 & 6 & 8 & 10 & 4 & 10 & 6 & 4 \\
\hline$C_{4}$ & 10 & 10 & 10 & 8 & 10 & 6 & 10 & 10 & 10 & 10 & 10 \\
\hline$C_{5}$ & 10 & 8 & 10 & 10 & 10 & 10 & 10 & 8 & 10 & 10 & 10 \\
\hline$C_{6}$ & 8 & 10 & 10 & 8 & 10 & 6 & 10 & 10 & 10 & 8 & 10 \\
\hline$C_{7}$ & 10 & 8 & 10 & 10 & 8 & 10 & 10 & 8 & 10 & 8 & 10 \\
\hline$C_{8}$ & 10 & 10 & 10 & 10 & 10 & 10 & 10 & 10 & 10 & 10 & 10 \\
\hline$C_{9}$ & 10 & 10 & 10 & 10 & 10 & 10 & 10 & 10 & 10 & 10 & 10 \\
\hline
\end{tabular}

By using the mean and standard deviation of each line of the decision matrix a Gaussian membership function can be utilized in order to minimize the spreading of the data (Oliveira et al., 2007). This approach is illustrated in Figure 1 for line 1 of the decision matrix.

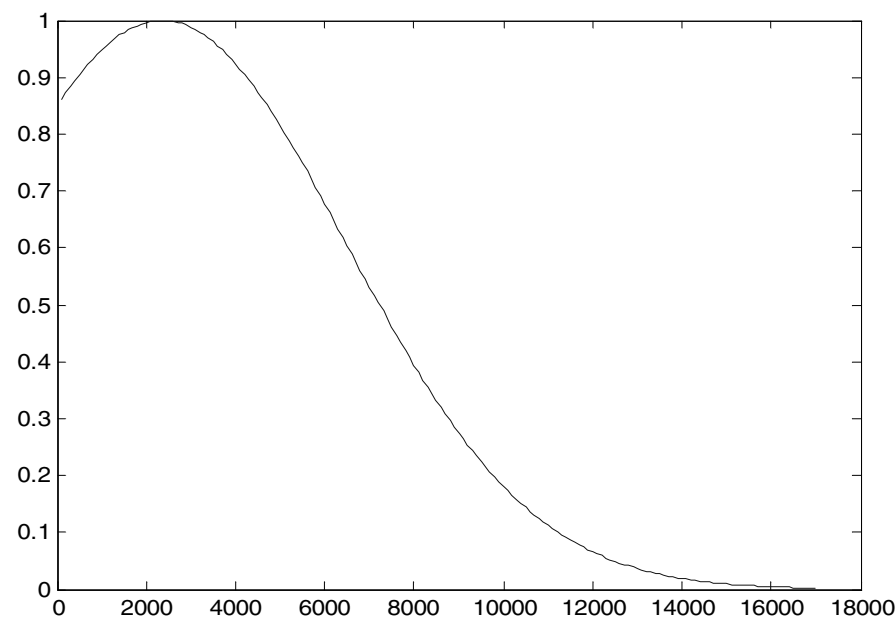

Figure 1 - Membership function adjusted to the data of line 1 of decision matrix.

The membership values for line 1 of the decision matrix are presented in Table 6 .

This task is accomplished for the whole decision matrix, as shown in Table 7. In this last table $m_{i}$ is the membership value for line $i$ of the decision matrix $(i=1, \ldots, 7)$.

The Choquet integral was calculated for all two portfolio combinations and for all possible two criteria combinations. The MinMax operator was used for each two of them. Similarly, all three portfolio combinations for all possible three criteria combinations were taken. Since criteria 8 and 9 are irrelevant for the analysis as they lead to the same figures they were removed from Table 8.

By applying these values, we obtain a new decision matrix, which is presented in Table 8 . 
Table 6 - Membership values for of the decision matrix.

\begin{tabular}{|c|c|}
\hline Project & Membership values \\
\hline$P_{1}$ & 0.93 \\
\hline$P_{2}$ & 0.89 \\
\hline$P_{3}$ & 0.89 \\
\hline$P_{4}$ & 0.98 \\
\hline$P_{5}$ & 0.89 \\
\hline$P_{6}$ & 0.93 \\
\hline$P_{7}$ & 0.01 \\
\hline$P_{8}$ & 0.94 \\
\hline$P_{9}$ & 0.94 \\
\hline$P_{10}$ & 0.95 \\
\hline$P_{11}$ & 0.97 \\
\hline
\end{tabular}

Table 7 - Membership values for all data of decision matrix.

\begin{tabular}{|c|c|c|c|c|c|c|c|}
\hline Project & $m_{1}$ & $m_{2}$ & $m_{3}$ & $m_{4}$ & $m_{5}$ & $m_{6}$ & $m_{7}$ \\
\hline$P_{1}$ & 0.93 & 0.85 & 0.60 & 0.90 & 0.90 & 0.55 & 0.91 \\
\hline$P_{2}$ & 0.89 & 0.79 & 0.99 & 0.90 & 0.10 & 0.66 & 0.45 \\
\hline$P_{3}$ & 0.89 & 0.02 & 0.60 & 0.90 & 0.90 & 0.66 & 0.77 \\
\hline$P_{4}$ & 0.98 & 0.91 & 0.99 & 0.50 & 0.90 & 0.55 & 0.77 \\
\hline$P_{5}$ & 0.89 & 0.91 & 0.99 & 0.90 & 0.90 & 0.66 & 0.45 \\
\hline$P_{6}$ & 0.93 & 0.99 & 0.70 & 0.02 & 0.90 & 0.01 & 0.77 \\
\hline$P_{7}$ & 0.91 & 0.88 & 0.21 & 0.90 & 0.90 & 0.66 & 0.77 \\
\hline$P_{8}$ & 0.94 & 0.91 & 0.60 & 0.90 & 0.10 & 0.66 & 0.45 \\
\hline$P_{9}$ & 0.94 & 0.95 & 0.21 & 0.90 & 0.90 & 0.66 & 0.77 \\
\hline$P_{10}$ & 0.95 & 0.68 & 0.99 & 0.90 & 0.90 & 0.55 & 0.45 \\
\hline$P_{11}$ & 0.97 & 0.79 & 0.60 & 0.90 & 0.90 & 0.66 & 0.77 \\
\hline
\end{tabular}

Table 8 - Fuzzified decision matrix for the SEBRAE-RJ case study.

\begin{tabular}{|c|c|c|c|c|c|c|c|c|c|c|c|}
\hline \multirow{2}{*}{ Criterion } & \multicolumn{10}{|c|}{ Projects } \\
\cline { 2 - 13 } & $P_{1}$ & $P_{2}$ & $P_{3}$ & $P_{4}$ & $P_{5}$ & $P_{6}$ & $P_{7}$ & $P_{8}$ & $P_{9}$ & $P_{10}$ & $P_{11}$ \\
\hline$C_{1}$ & 0.93 & 0.89 & 0.89 & 0.98 & 0.89 & 0.93 & 0.91 & 0.94 & 0.94 & 0.95 & 0.97 \\
\hline$C_{2}$ & 0.85 & 0.79 & 0.02 & 0.91 & 0.91 & 0.99 & 0.88 & 0.91 & 0.95 & 0.68 & 0.79 \\
\hline$C_{3}$ & 0.60 & 0.99 & 0.60 & 0.99 & 0.99 & 0.70 & 0.21 & 0.60 & 0.21 & 0.99 & 0.60 \\
\hline$C_{4}$ & 0.90 & 0.90 & 0.90 & 0.50 & 0.90 & 0.00 & 0.90 & 0.90 & 0.90 & 0.90 & 0.90 \\
\hline$C_{5}$ & 0.90 & 0.10 & 0.90 & 0.90 & 0.90 & 0.90 & 0.90 & 0.10 & 0.90 & 0.90 & 0.90 \\
\hline$C_{6}$ & 0.55 & 0.66 & 0.66 & 0.55 & 0.66 & 0.01 & 0.66 & 0.66 & 0.66 & 0.55 & 0.66 \\
\hline$C_{7}$ & 0.77 & 0.45 & 0.77 & 0.77 & 0.45 & 0.77 & 0.77 & 0.45 & 0.77 & 0.45 & 0.77 \\
\hline
\end{tabular}




\section{Step 1 - Determining the fuzzy measures}

As fuzzy measures indicate the degree of evidence that an element belongs to a set, considering a 2-aditive model and the Shapley-Schubik index, the fuzzy measures used in this paper were:

$$
\begin{array}{llll}
\mu(\{1,2,3,4,5,6,7,8,9\})=1, & \mu(\phi)=0, & \mu(\{1\})=0.56, & \mu(\{2\})=0, \\
\mu(\{3\})=0, & \mu(\{4\})=0, & \mu(\{5\})=0, & \mu(\{6\})=0, \\
\mu(\{7\})=0, & \mu(\{8\})=0, & \mu(\{9\})=0, & \mu(\{1,2\})=0.54, \\
\mu(\{1,3\})=0, & \mu(\{2,3\})=0.53, & \mu(\{3,4\})=0.49, & \mu(\{4,5\})=0.48, \\
\mu(\{5,6\})=0.45, & \mu(\{6,7\})=0.44 . &
\end{array}
$$

We then consider the following order of criteria: $C_{1} \succ C_{2} \succ C_{3} \succ C_{4} \succ C_{5} \succ C_{6} \succ C_{7}$.

\section{Step 2 - Choquet integral calculations}

\begin{tabular}{|c|c|c|c|c|}
\hline Criterion & Project \#1 & Project \#2 & Project \#1 & Project \#3 \\
\hline$C_{1}$ & $\begin{array}{l}0.93 \mu(\{1\}) \\
=0.93 \cdot 0.56 \\
=0.52\end{array}$ & $\begin{array}{l}0.89 \mu(\{1\}) \\
=0.89 \cdot 0.56 \\
=0.50\end{array}$ & $\begin{array}{l}0.93 \mu(\{1\}) \\
=0.93 \cdot 0.56 \\
=0.52\end{array}$ & $\begin{array}{l}0.89 \mu(\{1\}) \\
=0.89 \cdot 0.56 \\
=0.50\end{array}$ \\
\hline$C_{2}$ & $\begin{array}{l}(0.93-0.85) \mu(\{1,2\}) \\
=0.14\end{array}$ & $\begin{array}{l}(0.89-0.79) \mu(\{1,2\}) \\
=0.19\end{array}$ & $\begin{array}{l}(0.93-0.85) \mu(\{1,2\}) \\
=0.14\end{array}$ & $\begin{array}{l}(0.89-0.02) \mu(\{1,2\}) \\
=1.61\end{array}$ \\
\hline$C_{3}$ & $\begin{array}{l}(0.85-0.6) \mu(\{2,3\}) \\
=0.13\end{array}$ & $\begin{array}{l}(1-0.79) \mu(\{2,3\}) \\
=0.11\end{array}$ & $\begin{array}{l}(0.85-0.6) \mu(\{2,3\}) \\
=0.13\end{array}$ & $\begin{array}{l}(0.6-0.02) \mu(\{2,3\}) \\
=0.31\end{array}$ \\
\hline$C_{4}$ & $\begin{array}{l}(0.9-0.6) \mu(\{3,4\}) \\
=0.15\end{array}$ & $\begin{array}{l}(1-0.9) \mu(\{3,4\}) \\
=0.04\end{array}$ & $\begin{array}{l}(0.9-0.6) \mu(\{3,4\}) \\
=0.15\end{array}$ & $\begin{array}{l}(0.9-0.6) \mu(\{3,4\}) \\
=0.15\end{array}$ \\
\hline$C_{5}$ & $\begin{array}{l}(0.9-0.9) \mu(\{4,5\}) \\
=0\end{array}$ & $\begin{array}{l}(0.9-0.1) \mu(\{4,5\}) \\
=0.38\end{array}$ & $\begin{array}{l}(0.9-0.9) \mu(\{4,5\}) \\
=0\end{array}$ & $\begin{array}{l}(0.9-0.9) \mu(\{4,5\}) \\
=0\end{array}$ \\
\hline$C_{6}$ & $\begin{array}{l}(0.9-0.55) \mu(\{5,6\}) \\
=0.15\end{array}$ & $\begin{array}{l}(0.66-0.1) \mu(\{5,6\}) \\
=0.25\end{array}$ & $\begin{array}{l}(0.9-0.55) \mu(\{5,6\}) \\
=0.15\end{array}$ & $\begin{array}{l}(0.9-0.66) \mu(\{5,6\}) \\
=0.11\end{array}$ \\
\hline$C_{7}$ & $\begin{array}{l}(0.77-0.55) \mu(\{6,7\}) \\
=0.09\end{array}$ & $\begin{array}{l}(0.66-0.45) \mu(\{6,7\}) \\
=0.09\end{array}$ & $\begin{array}{l}(0.77-0.55) \mu(\{6,7\}) \\
=0.09\end{array}$ & $\begin{array}{l}(0.77-0.66) \mu(\{6,7\}) \\
=0.05\end{array}$ \\
\hline Min & $\begin{array}{l}\operatorname{Min}(0.52,0.14, \\
0.13,0.15,0, \\
0.15,0.09,0.50, \\
0.19,0.11,0.04, \\
0.38,0.25,0.09 \\
0.24,0.24)=0\end{array}$ & & $\begin{array}{l}\operatorname{Min}(0.52,0.14, \\
0.13,0.15,0, \\
0.15,0.09,0.50, \\
1.61,0.31,0.15, \\
0,0.11,0.05, \\
0.10,0.10)=0\end{array}$ & \\
\hline $\begin{array}{l}\text { Choquet } \\
\text { integral } \\
(\text { Max })\end{array}$ & $\begin{array}{l}\operatorname{Max}(0.52,0.14, \\
0.13,0.15,0, \\
0.15,0.09,0.50, \\
0.19,0.11,0.04, \\
0.38,0.25,0.09, \\
0.24,0.24)=0.52\end{array}$ & & $\begin{array}{l}\operatorname{Max}(0.52,0.14, \\
0.13,0.15,0, \\
0.15,0.09,0.50, \\
1.61,0.31,0.15, \\
0,0.11,0.05, \\
0.10,0.10)=1.61\end{array}$ & \\
\hline
\end{tabular}

In Table 9, we present some calculations obtained by using the bipolar Choquet integral for projects 1 and 2 and for projects 1 and 3. The same has been done for all combinations of two projects.

Table 9 - Some calculations for a two project selection of SEBRAE-RJ case study. 
These calculations are performed by using the Min and Max operators along considering the respective two columns projects. The MaxMin operator has been used to calculate the Choquet integral. The ranking of the alternatives that are provided by the Choquet integral is then obtained by ordering these alternatives from the highest to the lowest values.

The results are presented in Table 9.

\section{A two-combination choice}

The Choquet integral was calculated for all two portfolios combinations and all two criteria combinations that is, the MinMax operator was used for each two of them.

In Table 10 the ordering for two project combination portfolios is shown for the three most important criteria, $C_{1}$ (cost of project with mean 1193.88), $C_{2}$ (generated revenue/total cost of project with mean 0.17 ) and $C_{3}$ (degree of synergy in the use of SEBRAE-RJ's products in the project with mean 6.18).

In this paper values higher that mean values are considered as high; values near mean values are considered as mean; and values lower that mean values are considered as low. This holds for Tables 10, 11 and 12 .

It can be observed that project $P_{3}$ is present in all combinations for criteria that are related with minimum cost. high generated revenue and high synergy.

Table 11 presents a two combination choice for the criteria $C_{4}$ (capacity to contribute to the sustainable development of the region with mean 9.45), $C_{5}$ (capacity to interact with other sectors of the economy with mean 9.64) and $C_{6}$ (capacity to generate employment and income with mean 9.1).

It can be observed that most of combinations have high capacity to contribute to the sustainable development of the region, high capacity to interact with other sectors of the economy and high capacity to generate employment and income. It also can be seen that project $P_{3}$ is present in all of them. Table 12 presents a two combination choice for the criteria $C_{7}$ (degree of adherence of the partnerships) in the management as well as governance of the project with mean 9.3. In Table 12 criteria 8 and 9 were not considered since they were found to be redundant.

It can be observed that all combinations have high degree of adherence of the partnerships in the management as well as governance of the project, high chance of success and high degree of visibility that the project would bring to SEBRAE-RJ.

It also can be seen that project $P_{3}$ is present in all of them. In conclusion, we now reach the ordering by the bipolar Choquet integral for alternative two-project portfolios, as shown Table 13 presents the results obtained by using the bipolar Choquet integral for two-combination portfolios. Table 14 presents the results obtained by using the bipolar Choquet integral for three-project portfolio alternatives with similar calculations.

In the case of three-project portfolio alternatives, the Choquet integral was calculated for all three portfolios combinations and all three criteria combinations that is, the MinMax operator was used for each. 
Table 10 - A two combination choice based on the first three most important criteria $C_{1}, C_{2}$ and $C_{3}$.

\begin{tabular}{|c|c|c|c|c|}
\hline $\begin{array}{c}\text { A two } \\
\text { combination } \\
\text { choice }\end{array}$ & $C_{1}$ & $C_{2}$ & $C_{3}$ & Observations \\
\hline$P_{3}-P_{7}$ & $\begin{array}{c}343.93 \text { and } 2354.2 \\
\text { mean }=1349.07\end{array}$ & $\begin{array}{c}0.63 \text { and } 0.092 \\
\text { mean }=0.36\end{array}$ & $\begin{array}{l}4 \text { and } 10 \\
\text { mean }=7\end{array}$ & $\begin{array}{c}\text { low cost; } \\
\text { high generated revenue; } \\
\text { high synergy }\end{array}$ \\
\hline$P_{3}-P_{5}$ & $\begin{array}{c}343.93 \text { and } 327.55 \\
\text { mean }=335.74\end{array}$ & $\begin{array}{l}0.63 \text { and } 0.10 \\
\text { mean }=0.36\end{array}$ & $\begin{array}{c}4 \text { and } 6 \\
\text { mean }=5\end{array}$ & $\begin{array}{c}\text { low cost; } \\
\text { high generated revenue; } \\
\text { medium synergy }\end{array}$ \\
\hline$P_{3}-P_{6}$ & $\begin{array}{c}775.79 \text { and } 343.92 \\
\text { mean }=559.86\end{array}$ & $\begin{array}{l}0.08 \text { and } 0.63 \\
\text { mean }=0.36\end{array}$ & $\begin{array}{c}4 \text { and } 8 \\
\text { mean }=6\end{array}$ & $\begin{array}{c}\text { low cost; } \\
\text { high generated revenue; } \\
\text { medium synergy }\end{array}$ \\
\hline$P_{3}-P_{9}$ & $\begin{array}{c}343.93 \text { and } 929.54 \\
\text { mean }=636.74\end{array}$ & $\begin{array}{l}0.63 \text { and } 0.122 \\
\text { mean }=0.375\end{array}$ & $\begin{array}{l}4 \text { and } 10 \\
\text { mean }=7\end{array}$ & $\begin{array}{c}\text { low cost; } \\
\text { high generated revenue; } \\
\text { medium synergy }\end{array}$ \\
\hline$P_{3}-P_{8}$ & $\begin{array}{c}343.93 \text { and } 884.39 \\
\text { mean }=1349.07\end{array}$ & $\begin{array}{l}0.63 \text { and } 0.096 \\
\text { mean }=0.362\end{array}$ & $\begin{array}{c}4 \text { and } 4 \\
\text { mean }=4\end{array}$ & $\begin{array}{c}\text { low cost; } \\
\text { high generated revenue; } \\
\text { low synergy }\end{array}$ \\
\hline$P_{2}-P_{3}$ & $\begin{array}{c}393.06 \text { and } 343.93 \\
\text { mean }=368.5\end{array}$ & $\begin{array}{l}0.061 \text { and } 0.09 \\
\text { mean }=0.345\end{array}$ & $\begin{array}{c}6 \text { and } 4 \\
\text { mean }=5\end{array}$ & $\begin{array}{c}\text { low cost; } \\
\text { high generated revenue; } \\
\text { low synergy }\end{array}$ \\
\hline$P_{3}-P_{4}$ & $\begin{array}{c}343.93 \text { and } 1572.24 \\
\text { mean }=958.09\end{array}$ & $\begin{array}{l}0.63 \text { and } 0.1 \\
\text { mean }=0.36\end{array}$ & $\begin{array}{c}4 \text { and } 6 \\
\text { mean }=5\end{array}$ & $\begin{array}{c}\text { low cost; } \\
\text { high generated revenue; } \\
\text { low synergy }\end{array}$ \\
\hline$P_{1}-P_{3}$ & $\begin{array}{c}343.93 \text { and } 343.93 \\
\text { mean }=614.16\end{array}$ & $\begin{array}{c}0.63 \text { and } 0.192 \\
\text { mean }=0.41\end{array}$ & $\begin{array}{c}4 \text { and } 4 \\
\text { mean }=4\end{array}$ & $\begin{array}{c}\text { low cost; } \\
\text { high generated revenue; } \\
\text { low synergy }\end{array}$ \\
\hline$P_{3}-P_{10}$ & $\begin{array}{c}343.93 \text { and } 982.67 \\
\text { mean }=663.3\end{array}$ & $\begin{array}{c}0.63 \text { and } 0.305 \\
\text { mean }=0.47\end{array}$ & $\begin{array}{c}4 \text { and } 6 \\
\text { mean }=5\end{array}$ & $\begin{array}{c}\text { low cost; } \\
\text { high generated revenue; } \\
\text { low synergy }\end{array}$ \\
\hline$P_{3}-P_{11}$ & $\begin{array}{c}343.93 \text { and } 3684.94 \\
\text { mean }=2014.44\end{array}$ & $\begin{array}{l}0.63 \text { and } 0.064 \\
\text { mean }=0.346\end{array}$ & $\begin{array}{c}4 \text { and } 4 \\
\text { mean }=4\end{array}$ & $\begin{array}{c}\text { low cost; } \\
\text { high generated revenue; } \\
\text { low synergy }\end{array}$ \\
\hline
\end{tabular}

It can be observed that all projects are selected to compose a three-combination choice of portfolio for all nine criteria and the project $P_{3}$ is present in all.

\section{CONCLUSIONS}

We have concluded that the bipolar Choquet integral is adequate for solving multiple choice problems. As an application example, we have used the bipolar Choquet integral to show how SEBRAE-RJ can determine which two or three project combination choices should be formed. 
Table 11 - A two combination choice based on criteria $C_{4}, C_{5}$ and $C_{6}$.

\begin{tabular}{|c|c|c|c|c|}
\hline $\begin{array}{l}\text { A two-combination } \\
\text { choice }\end{array}$ & $C_{4}$ & $C_{5}$ & $C_{6}$ & Observations \\
\hline$P_{3}-P_{5}$ & $\begin{array}{l}10 \text { and } 10 \\
\text { mean }=10\end{array}$ & $\begin{array}{l}10 \text { and } 10 \\
\text { mean }=10\end{array}$ & $\begin{array}{l}10 \text { and } 10 \\
\text { mean }=10\end{array}$ & $\begin{array}{l}\text { high capacity to contribute to the } \\
\text { sustainable development of the region; } \\
\text { high capacity to interact with other sectors } \\
\text { of the economy; high capacity to generate } \\
\text { employment and income }\end{array}$ \\
\hline$P_{3}-P_{7}$ & $\begin{array}{c}10 \text { and } 10 \\
\text { mean }=10\end{array}$ & $\begin{array}{l}10 \text { and } 10 \\
\text { mean }=10\end{array}$ & $\begin{array}{l}10 \text { and } 10 \\
\text { mean }=10\end{array}$ & $\begin{array}{l}\text { high capacity to contribute to the } \\
\text { sustainable development of the region; } \\
\text { high capacity to interact with other sectors } \\
\text { of the economy; high capacity to generate } \\
\text { employment and income }\end{array}$ \\
\hline$P_{3}-P_{9}$ & $\begin{array}{l}10 \text { and } 10 \\
\text { mean }=10\end{array}$ & $\begin{array}{l}10 \text { and } 10 \\
\text { mean }=10\end{array}$ & $\begin{array}{l}10 \text { and } 10 \\
\text { mean }=10\end{array}$ & $\begin{array}{l}\text { high capacity to contribute to the } \\
\text { sustainable development of the region; } \\
\text { high capacity to interact with other sectors } \\
\text { of the economy; high capacity to generate } \\
\text { employment and income }\end{array}$ \\
\hline$P_{3}-P_{11}$ & $\begin{array}{c}10 \text { and } 10 \\
\text { mean }=10\end{array}$ & $\begin{array}{l}10 \text { and } 10 \\
\text { mean }=10\end{array}$ & $\begin{array}{l}10 \text { and } 10 \\
\text { mean }=10\end{array}$ & $\begin{array}{l}\text { high capacity to contribute to the } \\
\text { sustainable development of the region; } \\
\text { high capacity to interact with other sectors } \\
\text { of the economy; high capacity to generate } \\
\text { employment and income }\end{array}$ \\
\hline$P_{1}-P_{3}$ & $\begin{array}{l}10 \text { and } 10 \\
\text { mean }=10\end{array}$ & $\begin{array}{l}10 \text { and } 10 \\
\text { mean }=10\end{array}$ & $\begin{array}{l}8 \text { and } 10 \\
\text { mean }=9\end{array}$ & $\begin{array}{l}\text { high capacity to contribute to the } \\
\text { sustainable development of the region; } \\
\text { high capacity to interact with other sectors } \\
\text { of the economy; medium capacity to } \\
\text { generate employment and income }\end{array}$ \\
\hline
\end{tabular}

All of the selected two- and three-project combination portfolios do not cost too much and lead to high generated revenues/total project cost, high capacity to contribute to the sustainable development of the region and high capacity to create employment and income. For a two-choice problem, projects $P_{2}, P_{4}, P_{5}, P_{8}$ and $P_{10}$ are not selected, and for a three-choice problem, all projects are selected. In essence, we have shown that the use of the bipolar Choquet integral could allow forming a portfolio of projects by considering the measures of interactions among criteria. However, one must keep in mind the limitations that are related to the use of the Choquet integral, such as the requirement to have the aggregation (e.g., utility) functions fixed a priori (Bouyssou et al., 2012). Nevertheless, when the bipolar Choquet integral can be used, the approach presented in this paper can be extended for $n=3$ by induction.

An algorithm for the solution of a generic multiple choice problem based on the bipolar Choquet integral can be a generalization of a two portfolio choice. The steps to be followed should then be following: (1) determine the fuzzy measures to indicate the degree of evidence 
Table 12 - A two combination choice based on criteria $C_{7}$.

\begin{tabular}{|c|c|c|}
\hline $\begin{array}{c}\text { A two-combination } \\
\text { choice }\end{array}$ & $C_{7}$ & Observations \\
\hline$P_{1}-P_{3}$ & $\begin{array}{l}10 \text { and } 10 \\
\text { mean }=10\end{array}$ & $\begin{array}{l}\text { high degree of adherence of the partnerships } \\
\text { in the management as well as governance of the project; } \\
\text { high chance of success; high degree of visibility } \\
\text { that the project would bring to SEBRAE-RJ; } \\
\text { capacity to generate employment and income }\end{array}$ \\
\hline$P_{3}-P_{4}$ & $\begin{array}{l}10 \text { and } 10 \\
\text { mean }=10\end{array}$ & $\begin{array}{l}\text { high degree of adherence of the partnerships } \\
\text { in the management as well as governance of the project; } \\
\text { high chance of success; high degree of visibility } \\
\text { that the project would bring to SEBRAE-RJ; } \\
\text { capacity to generate employment and income }\end{array}$ \\
\hline$P_{3}-P_{6}$ & $\begin{array}{c}10 \text { and } 10 \\
\text { mean }=10\end{array}$ & $\begin{array}{l}\text { high degree of adherence of the partnerships } \\
\text { in the management as well as governance of the project; } \\
\text { high chance of success; high degree of visibility } \\
\text { that the project would bring to SEBRAE-RJ; } \\
\text { capacity to generate employment and income }\end{array}$ \\
\hline$P_{3}-P_{7}$ & $\begin{array}{c}10 \text { and } 10 \\
\text { mean }=10\end{array}$ & $\begin{array}{l}\text { high degree of adherence of the partnerships } \\
\text { in the management as well as governance of the project; } \\
\text { high chance of success; high degree of visibility } \\
\text { that the project would bring to SEBRAE-RJ; } \\
\text { capacity to generate employment and income }\end{array}$ \\
\hline$P_{3}-P_{9}$ & $\begin{array}{c}10 \text { and } 10 \\
\text { mean }=10\end{array}$ & $\begin{array}{l}\text { high degree of adherence of the partnerships } \\
\text { in the management as well as governance of the project; } \\
\text { high chance of success; high degree of visibility } \\
\text { that the project would bring to SEBRAE-RJ; } \\
\text { capacity to generate employment and income }\end{array}$ \\
\hline$P_{3}-P_{11}$ & $\begin{array}{c}10 \text { and } 10 \\
\text { mean }=10\end{array}$ & $\begin{array}{l}\text { high degree of adherence of the partnerships } \\
\text { in the management as well as governance of the project; } \\
\text { high chance of success; high degree of visibility } \\
\text { that the project would bring to SEBRAE-RJ; } \\
\text { capacity to generate employment and income }\end{array}$ \\
\hline
\end{tabular}

that an element belongs to a set, considering a 2-additive model and the Shapley-Schubik index; (2) select a two portfolio alternative and calculate the bipolar Choquet integral for all two portfolio combinations and all two criteria combinations by using the MinMax operator for each combination; (3) for a three- project portfolio alternatives, the Choquet integral has to be calculated for all three portfolio combinations and all three criteria combinations that is, the MinMax operator has to be used for each of them; (4) and the same calculations can carried out for more than three projects selection. All these operations can be performed, as they were in this paper, by using a MATLAB program. 
Table 13 - Ordering by the Choquet bipolar Integral for two-choice projects 2.

\begin{tabular}{|c|c|}
\hline $\begin{array}{c}\text { Two-combination } \\
\text { Portfolios }\end{array}$ & $\begin{array}{c}\text { Results obtained using } \\
\text { the bipolar Choquet Integral }\end{array}$ \\
\hline$P_{3}-P_{7}$ & 1 \\
\hline$P_{3}-P_{9}$ & 2 \\
\hline$P_{3}-P_{6}$ & 3 \\
\hline$P_{3}-P_{9}$ & 4 \\
\hline$P_{3}-P_{11}$ & 5 \\
\hline
\end{tabular}

Table 14 - Ordering obtained using the bipolar Choquet Integral for three-combination portfolios.

\begin{tabular}{|c|c|}
\hline $\begin{array}{c}\text { Three-combination } \\
\text { Portfolios }\end{array}$ & $\begin{array}{c}\text { Results obtained using } \\
\text { the bipolar Choquet Integral }\end{array}$ \\
\hline$P_{1}-P_{2}-P_{3}$ & 1 \\
\hline$P_{1}-P_{3}-P_{6}$ & 2 \\
\hline$P_{1}-P_{3}-P_{8}$ & 3 \\
\hline$P_{1}-P_{3}-P_{9}$ & 4 \\
\hline$P_{1}-P_{3}-P_{10}$ & 5 \\
\hline$P_{1}-P_{3}-P_{11}$ & 6 \\
\hline$P_{2}-P_{3}-P_{4}$ & 7 \\
\hline$P_{2}-P_{3}-P_{7}$ & 8 \\
\hline
\end{tabular}

For future research, it is recommended to design and run detailed sensitivity analyses on using other types of membership functions and alternative values for the parameters.

\section{ACKNOWLEDGMENTS}

The research leading to this article was partially supported by CNPq through projects 305732/2012-9 and 303363/2014-2.

\section{REFERENCES}

[1] Anagnostopoulos KP \& Mamanis G. 2010. A portfolio optimization model with three objectives and discrete variables. Computers \& Operations Research, 37: 1285-1297.

[2] Bouyssou D, Couceiro M, Labreuche C, Marichal JL \& Mayag B. 2012. Using Choquet integral in Machine Learning: what can MCDA bring? DA2PL November 2012. LAMSADE, Université Paris.

[3] ČANČER V. 2010. Considering interactions among multiple criteria for the server selection. Journal of Information and Organizational Sciences, 34(1): 55-65.

[4] Carazo AF, Gomez T, Molina J, Hernandez-Diaz AG, Guerrero FM \& Caballero R. 2010. Solving a comprehensive model for multiobjective project portfolio selection. Computers \& Operations Research, 37: 630-639. 
[5] Choquet G. 1953. Theory of Capacities. Annales de l'Institut Fourier, 5: 131-295.

[6] Dalalah D, Al-Tahat M \& Bataineh K. 2012. Mutually dependendt multi-criteria decision making. Fuzzy Information Engineering, 2: 195-216.

[7] Dubois D, FArgier H \& Prade HM. 1996. Refinements of the maximin approach to decisionmaking in a fuzzy environment. Fuzzy Sets and Systems, 81(1): 103-122.

[8] Gomes LFAM, RANGel LAD \& Moreira RA. 2009. Using ELECTRE IV in the promotion of social and economic development: A case study in Rio de Janeiro. Foundations of Computing and Decision Sciences, 34(3).

[9] Grabisch M \& Labreuche C. 2005. Bi-capacities: The Choquet integral. Fuzzy Sets and Systems, 151(2): 237-259.

[10] Grabisch M \& Labreuche C. 2010. A Decade of the Choquet ans Sugeno integrals in MulticriteriA Decision Aid. Annals of Operations Research, 175: 247-290.

[11] Greco S \& Figueira J. 2003. Dealing with interaction between bi-polar multiple criteria preferences in outranking methods. Research Report 11-2003: 1-73. INESC - Coimbra, Portugal.

[12] HE XD \& ZHOU XY. 2011. Portfolio choice under cumulative prospect theory: An analytical treatment. Management Science, 57(2): 315-331.

[13] ÖZTÜRK ZK. 2006. A review of multi criteria decision making with dependency between criteria. MCDM 2006, Chania, Greece, June 19-23.

[14] Roy B. 2009. À propos de la signification des dépendences entre critères: quelle place et quels modes de prise em compte pour l'aide à la décision? RAIRO-Oper. Res., 43: 255-275.

[15] Sugeno M. 1974. Theory of fuzzy Integrals and its applications. PhD thesis. Tokyo Institute of Technology.

[16] Vetschera R \& Almeida AT DE. 2012. A PROMÉTHÉE-based approach to portfolio selection problems. Computers \& Operations Research, 39: 1010-1020.

[17] YU L, WANG S, WEN F \& LAI KK. 2012. Genetic algorithm-based multi-criteria project portfolio selection. Annals of Operations Research, 197: 71-86. 